\title{
Modulation of Rat Tissue Galactose-1-Phosphate Uridyltransferase by Uridine and Uridine Triphosphate
}

\author{
SHIRLEY ROGERS AND STANTON SEGAL \\ Division of Biochemical Development and Molecular Diseases, Children's Hospital of Philadelphia and \\ Departments of Pediatrics and Medicine, University of Pennsylvania School of Medicine, \\ Philadelphia, Pennsylvania 19104
}

\begin{abstract}
Uridine-containing sugar nucleotides, uridine diphosphate (UDP) -glucose and UDPgalactose are important intermediates in galactose metabolism, and tissue UDPgalactose may be a salient factor in the etiology of the long-term clinical manifestations of patients with galactose-1-phosphate uridyltransferase deficient galactosemia. Because uridine and uridine nucleotides such as uridine triphosphate (UTP) are known inhibitors of rat hepatic transferase, we have examined the effects of these compounds on the activity of the enzyme in homogenates of rat brain and ovary which are target organs of galactose toxicity in classical galactosemia. In addition, the concerted effect of uridine and UTP together on hepatic transferase has been assessed. These investigations have been prompted by considerations that uridine administration may have a therapeutic role in the long-term treatment of classical galactosemia. Both uridine and UTP have been found to be potent inhibitors of brain and ovarian transferase activity. Brain enzyme activity is more sensitive to these compounds than is that of the ovary. They are competitive inhibitors of UDPglucose in both newborn and adult brain enzyme preparations with a $k_{i}$ of 0.15 to 0.20 mM. Uridine and UTP at low concentrations were found to have an additive effect on rat hepatic transferase activity, which is especially significant in that uridine administration is known to increase hepatic UTP concentration. These findings suggest judicious caution should be used in giving uridine to patients with genetically limited transferase activity because the possibility exists of inhibiting small amounts of residual enzyme in the tissues of affected subjects. (Pediatr Res 30: 222-226, 1991)
\end{abstract}

\section{Abbreviations}

UDPglucose, uridine diphosphate glucose

UDPgalactose, uridine diphosphate galactose

UTP, uridine triphosphate

Transferase, $\alpha$-D-galactose-1-phosphate uridyltransferase (EC 2.7.7.12)

A recent analysis (1) of the outcome of long-term dietary therapy in the treatment of galactose-1-phosphate uridyltransferase deficiency galactosemia (classical disease) indicates that a galactose-free diet appears unable to prevent some degree of

Received February 26, 1991; accepted May 13, 1991.

Reprint requests: Stanton Segal, M.D., Division of Biochemical Development and Molecular Diseases, Children's Hospital of Philadelphia, 34th Street \& Civic Center Boulevard, Philadelphia, PA 19104.

Supported by National Institutes of Health Grant DK 42785 mental retardation or ovarian failure in most females. In addition, a neurologic ataxia syndrome has appeared in some patients after many years of galactose restriction (2). These observations emphasize the fact that the pathophysiology of uridyltransferase deficiency and galactose toxicity in this disorder remain enigmatic. The etiology of brain, ovary, and liver dysfunction are unclear although galactitol accumulation in the lens is associated with cataracts (3).

The uridine-containing sugar nucleotides, UDPglucose and UDPgalactose, play salient roles as substrates and products of both transferase and UDPgalactose 4-epimerase, enzymes in the pathway of galactose conversion to glucose (4). Two theories involving these substances have been proposed as the basis of long-term complications despite elimination of dietary galactose. That of Gitzelmann et al. (5) espouses a continuous self-intoxication due to endogenous production of galactose-1-phosphate from UDPgalactose formed from UDPglucose by epimerase activity. A more recent postulate of $\mathrm{Ng}$ et al. (6) based on a finding of low UDPgalactose in galactosemic cells proposes that a deficiency of UDPgalactose limits the formation of complex galactose-containing substances such as glycoproteins and galactolipids normally requiring UDPgalactose as a precursor. Kaufman et al. have instituted the treatment of galactosemic patients with uridine $(7,8)$ on the basis of the finding that incubation of UDPgalactose-deficient galactosemic red cells with uridine restores their UDPgalactose content (6).

The intimate involvement of UDPglucose and UDPgalactose in the galactose metabolic pathway led us to focus on the role of cellular uridine-containing nucleotides in the regulation of the activity of galactose-metabolizing enzymes. We showed that uridine monophosphate, UDP, and UTP were inhibitors of rat liver galactose-1-phosphate uridyltransferase (9). Recently, we reported that uridine itself was a potent inhibitor of hepatic transferase, being competitive with UDPglucose in the reaction and uncompetitive with galactose-1-phosphate (10). The uridine $\mathrm{k}_{\mathrm{i}}$ and the degree of its inhibition are similar to those observed for UTP, which was shown to be the most potent of nucleotide inhibitors (9). Indeed, it had been known since 1966 that uridine can markedly inhibit the oxidation of $1-{ }^{14} \mathrm{C}$-galactose by normal human red blood cells (11).

The administration of uridine to galactosemic patients has raised some concern (10) that increased tissue uridine content of galactosemics could inhibit residual transferase, thereby impairing any remnant of ability to metabolize galactose-1-phosphate endogenously produced from UDPgalactose as postulated by Gitzelmann et al. (5) or formed from exogenous food sources. This apprehension was augmented by the observations that administration of uridine to rats increases hepatic UTP (12) and that perfusion of suckling rat liver with uridine and galactose results in a threefold enhancement of UTP concentration and a concomitant increase in galactose-1-phosphate (10). The fact 
that uridine is an inhibitor and that its administration increases the hepatic concentration of a second inhibitor, UTP, prompted us to consider that dual elevation of uridine and UTP can have a combined effect on uridyltransferase activity.

The present studies have a twofold purpose. The first is to examine the effects of uridine and UTP on uridyltransferase activity of tissues such as brain and ovary which are the target organs of galactosemia. The second is to discern the resultant effects on hepatic uridyltransferase when uridine and UTP are elevated in concert. Our results form the basis of this report.

\section{MATERIALS AND METHODS}

Adult rats, aged 70-90 days, and timed-pregnant rats purchased from Charles River Breeding Laboratories, Inc. (Wilmington, MA) had free access to food and water. The offspring of the mothers were the neonates used in this study. Animals were killed by exsanguination, and the liver and brain were excised and rapidly frozen by the freeze-clamp technique. The intestine was rinsed by forcing ice-cold physiologic saline through the lumen and the jejunum was removed, opened longitudinally, blotted gently, and the mucosa was scraped and frozen. The ovaries were cleaned of fatty tissue before freezing between blocks of dry ice. This work was performed under approval by the Children's Hospital Animal Care and Use Committee.

Biochemicals were obtained from Sigma Chemical Co. (St. Louis, MO), $\left[{ }^{14} \mathrm{C}\right]$ galactose-1-phosphate was a product of Amersham Corp. (Arlington Heights, IL), DEAE cellulose ion exchange paper was a product of Whatman Inc. (Clifton, NJ), and all other chemicals of the highest purity available came from local suppliers.

The enzyme preparation was that described previously by Bertoli and Segal (13) and was used for assay of the effects of uridine nucleotides (9) and uridine (10) on hepatic uridyltransferase. Each tissue was homogenized in 8 vol of $0.1 \mathrm{M} \mathrm{KCl}$ and centrifuged at $30000 \times g$, and the clear supernatant was removed with care taken to avoid the lipid layer when present. The soluble fraction of liver was diluted 5-fold further with water and that of ovary was diluted 2.5 -fold, whereas enzyme from brain and intestine was used without further dilution.

Transferase was assayed by the procedure of Bertoli and Segal (13) which has been used in a series of reports from this laboratory on regulation of the enzyme activity (14-16). Measurement of the substrate concentration dependence was performed over a substrate range of $0.05-2 \mathrm{mmol} / \mathrm{L}$. To simplify the calculation of enzyme velocities and to eliminate isotope dilution as a cofactor, the radiolabeled substrate was kept at a fixed concentration and the concentration of nonradiolabeled substrate was varied. Thus, $\left[{ }^{14} \mathrm{C}\right]$ galactose-1-phosphate was fixed when UDPglucose was varied. All assays were determined by using linear initial rates of reaction and protein concentrations within the range of proportionality of the reaction. Data from the inhibition studies were plotted by the methods of Lineweaver and Burk (17) and Dixon (18). The type of inhibition was discerned from these plots by the criteria of Webb (19). Apparent $\mathrm{k}_{\mathrm{i}}$ values were calculated from the intersection of lines in the Dixon plot. Enzyme sp act are expressed as nanomoles of product formed per minute per milligram of soluble protein.

Each datum point represents the average \pm SEM for $n$ animals. Levels of significance were determined by $t$ test where $p<0.05$ is an acceptable difference. Analysis of variance was also used to compare the data for brain and ovary.

\section{RESULTS}

Effect of uridine on tissue galactose-1-phosphate uridyltransferase activity. The addition of $0.4 \mathrm{mM}$ uridine, a concentration shown previously to maximally inhibit rat liver transferase sp act (10), caused a significant decrease in the enzyme sp act of adult rat brain, ovary and intestine as well as liver (Table 1). In this
Table 1. Effect of uridine and UTP on adult tissue galactose-1-phosphate uridyltransferase sp act*

\begin{tabular}{|c|c|c|c|}
\hline Tissue & Control & $\begin{array}{c}\text { Uridine } \\
\mathrm{nmol} / \mathrm{min} / \mathrm{mg} / \text { protein }\end{array}$ & UTP \\
\hline Brain & $2.65 \pm 0.15$ & $1.10 \pm 0.03 \dagger$ & $1.25 \pm 0.07 \dagger$ \\
\hline Ovary & $11.58 \pm 0.94$ & $6.29 \pm 0.44 \ddagger$ & $7.50 \pm 0.49 \ddagger$ \\
\hline Intestine & $3.12 \pm 0.06$ & $2.27 \pm 0.12 \dagger$ & $1.34 \pm 0.06 \dagger$ \\
\hline Liver & $10.52 \pm 0.77$ & $5.35 \pm 0.34 \dagger$ & $6.10 \pm 0.36 \neq$ \\
\hline
\end{tabular}

* Concentration of uridine and UTP is $0.4 \mathrm{mM}$. Data are means \pm SEM for four animals.

$\dagger p<0.001$ compared with control.

$\ddagger p<0.01$ compared with control.

study, the liver enzyme was inhibited about $50 \%$, an extent comparable to that seen in our earlier report (10). The level of ovarian enzyme activity was surprisingly high and not unlike that of the liver which is the tissue recognized for its high capacity for galactose metabolism. The degree of uridine inhibition of the ovarian and liver enzyme was similar. Brain and intestinal mucosa activities were low compared with that of the other two tissues. The brain enzyme demonstrated a $58 \%$ inhibition whereas that of intestine was only $27 \%$.

Another experiment was performed to examine the effects of 0.1 to $0.4 \mathrm{mM}$ uridine on the brain and ovarian enzyme. The brain enzyme was inhibited to a greater extent than was the ovary enzyme (38 versus $28 \%$ at $0.1 \mathrm{mM}$ ) (Fig. 1). The data for all concentrations of uridine in Figure 1 were analyzed by analysis of variance which indicated the inhibition of the brain transferase was significantly greater from that seen with the ovarian enzyme with $p<0.001$.

The effect of uridine on the concentration-velocity dependence of UDPglucose as the substrate of newborn brain uridyltransferase is shown in Figure 2. Uridine is a competitive inhibitor of UDPglucose. As seen in Table 2, the apparent $\mathrm{Km}$ is increased 2.5 -fold by $0.4 \mathrm{mM}$ uridine. The $\mathrm{k}_{\mathrm{i}}$, the concentration of inhibitor that doubles the slope of the line of uninhibited enzyme (Fig. 2), was calculated to be $0.15 \mathrm{mM}$.

The enzyme from adult rat brain was studied in three replicate experiments under conditions identical to that shown in Figure 2. Similar results were obtained in the adult enzyme as seen for newborn brain transferase. Uridine affected a fourfold increase in the apparent $\mathrm{Km}(p<0.01)$ without a change in $\mathrm{V}_{\max }$. The calculated $\mathrm{k}_{\mathrm{i}}$ was $0.18 \mathrm{mM}$, indicating that the sensitivity of both newborn and adult brain transferase to uridine inhibition is essentially the same.

Effect of UTP on galactose-1-phosphate uridyltransferase. Table 1 reveals that UTP at $0.4 \mathrm{mM}$ causes an inhibition of liver, brain, and ovarian transferase sp act similar to that seen with uridine. The intestinal mucosal enzyme, on the other hand, is inhibited by UTP to a significantly greater extent than it is by uridine (58 versus 27\%). Figure 1 also shows that UTP at 0.15 $\mathrm{mM}$ produces significant inhibition of brain and ovarian enzyme. The $38 \%$ inhibition of brain transferase differs from the $24 \%$ of ovary by $p<0.05$.

Figure 2 demonstrates the effect of $0.4 \mathrm{mM} \mathrm{UTP}$ on the concentration-velocity dependence of the newborn brain enzyme. The inhibition is competitive with threefold increase in the apparent $\mathrm{Km}$ for UDPglucose without alteration of $\mathrm{V}_{\max }$ (Table 2). The UTP $\mathrm{k}_{\mathrm{i}}$ was $0.15 \mathrm{mM}$, identical to that for uridine. Similar findings were made with adult rat brain transferase with a calculated UTP $\mathrm{k}_{\mathrm{i}}$ of $0.20 \mathrm{mM}$.

Combined effect of uridine and UTP on hepatic galactose-1phosphate uridyltransferase. Because the administration of uridine to adult rats increased hepatic UTP (12) and the perfusion of suckling rat liver with uridine trebles the concentration of UTP (10), experiments were performed to determine the inhibition of both adult and newborn liver transferase when the enzyme activity was measured in the presence of both compounds. The results were the same with the hepatic enzyme from animals of 


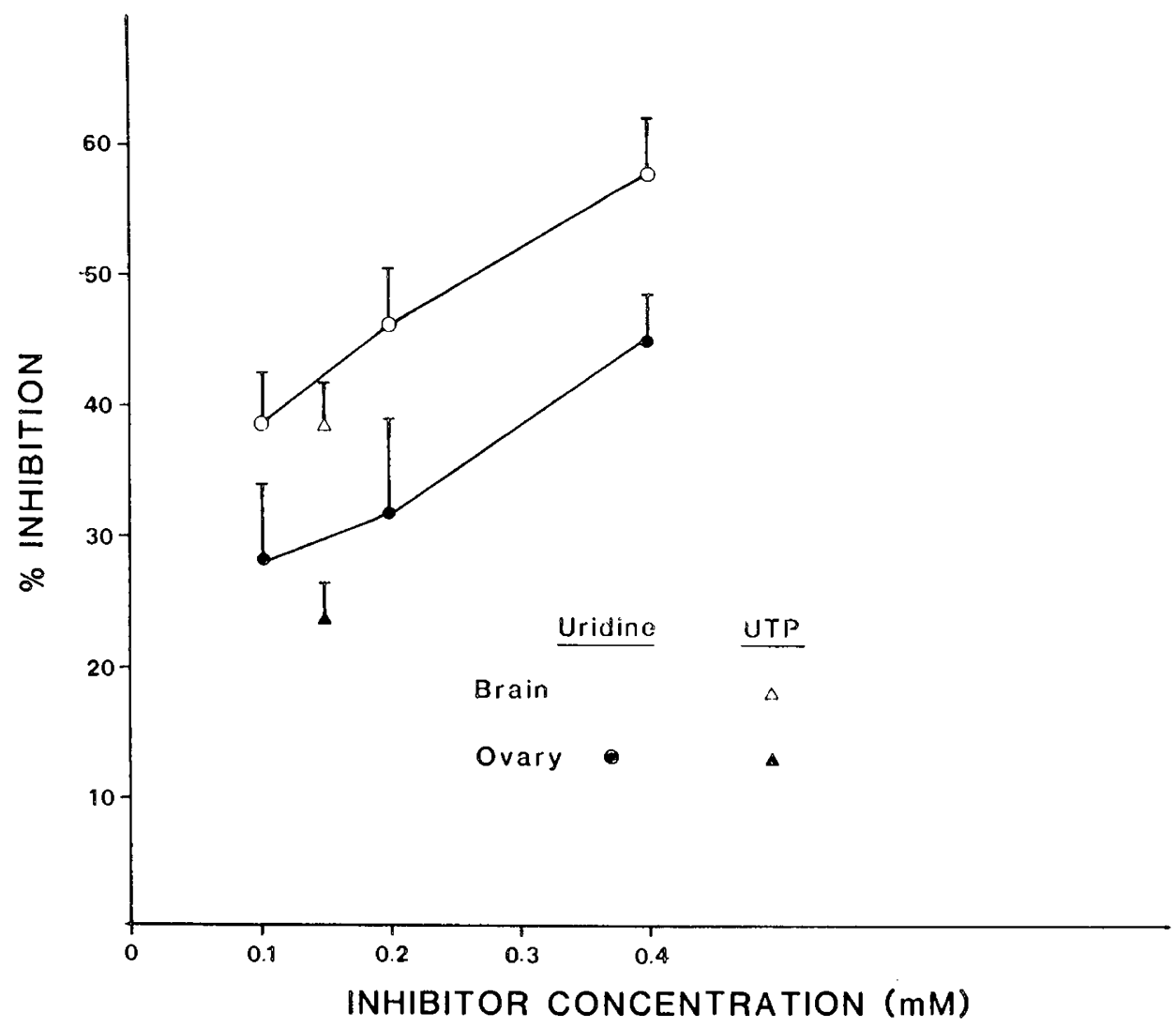

Fig. 1. Inhibition of galactose-1-phosphate uridyltransferase in rat brain and ovary by uridine and UTP. Datum points represent the average \pm SEM from three to four animals.

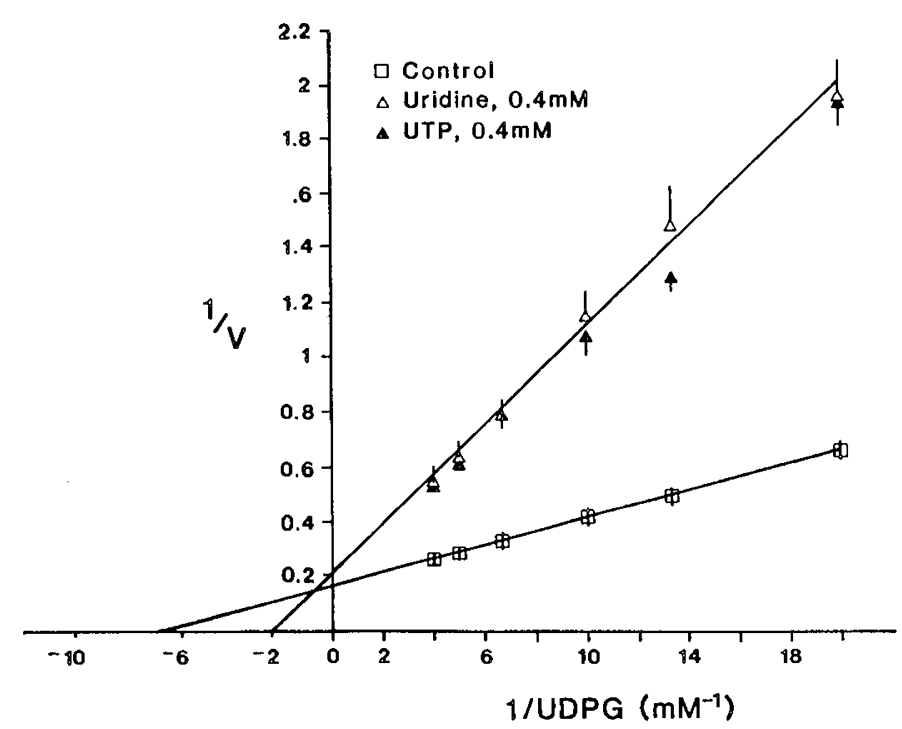

Fig. 2. Effect of uridine and UTP on the concentration dependence of transferase in newborn rat brain with respect to UDPglucose. Lines shown were calculated by linear regression analysis of data obtained from the control and from when uridine was present. Datum points represent the average of velocities (nanomoles of product formed per minute per milligram of soluble protein) \pm SEM from six experiments. Tissue from three to four newborn animals was pooled to obtain sufficient samples for each experiment.

both ages as shown in Figure 3. UTP alone causes increasing inhibition as its concentration is increased. The highest concentration of UTP used in these studies was $0.4 \mathrm{mM}$. In our earlier report (9), concentrations of UTP of $1 \mathrm{mM}$ caused $99 \%$ inhibition and the kinetic analysis indicated UTP was a linear com-
Table 2. Change in newborn brain GALT kinetic parameters for UDPglucose by uridine and UTP*

\begin{tabular}{lccc}
\hline & $\begin{array}{c}\text { Apparent Km } \\
(\mathrm{mM})\end{array}$ & $\begin{array}{c}\mathrm{V}_{\max } \\
(\mathrm{nmol} / \mathrm{min} / \mathrm{mg})\end{array}$ & $\begin{array}{c}\mathrm{k}_{\mathrm{i}} \\
(\mathrm{mM})\end{array}$ \\
\hline Control & $0.15 \pm 0.01$ & $6.4 \pm 0.42$ & \\
Uridine & $0.37 \pm 0.02 \dagger$ & $4.5 \pm 0.33$ & 0.15 \\
UTP & $0.50 \pm 0.05 \dagger$ & $5.6 \pm 0.71$ & 0.15 \\
\hline
\end{tabular}

* Concentration of uridine and UTP was $0.4 \mathrm{mM}$. Mean and SEM of six experiments. GALT, galactose-1-phosphate uridyltransferase.

$\dagger p<0.001$ compared with control.

petitive inhibitor. At lower concentrations of uridine, the combined effect of both inhibitors was greatest and was almost additive (Fig. 3). As the uridine concentration was increased, the effect of increasing UTP diminished. Likewise, as the concentration of UTP increased, the effect of uridine was lessened. Uridine alone has been shown to have a maximal effect at $0.4 \mathrm{mM}$ and is a nonlinear competitive inhibitor (10). It appears that the increased concentration of the uridine moiety at the lower concentrations of both exerts a combined effect. Indeed, in a separate experiment, $0.05 \mathrm{mM}$ uridine, which exerted a $12-14 \%$ (Fig. 3) inhibition, when combined with $0.1 \mathrm{mM}$ UTP produced a $21 \%$ inhibition. It thus appears that meaningful inhibition of transferase activity can be initiated with physiologic cellular concentrations of UTP $(10,12,20)$ and that relatively low concentrations of uridine superimposes an additional impediment to enzyme function.

\section{DISCUSSION}

The data presented here indicate that uridine and UTP are inhibitors of galactose-1-phosphate uridyltransferase, not only in liver but also in brain and ovary, which are target organs of galactose toxicity. The degree of sensitivity of transferase to 

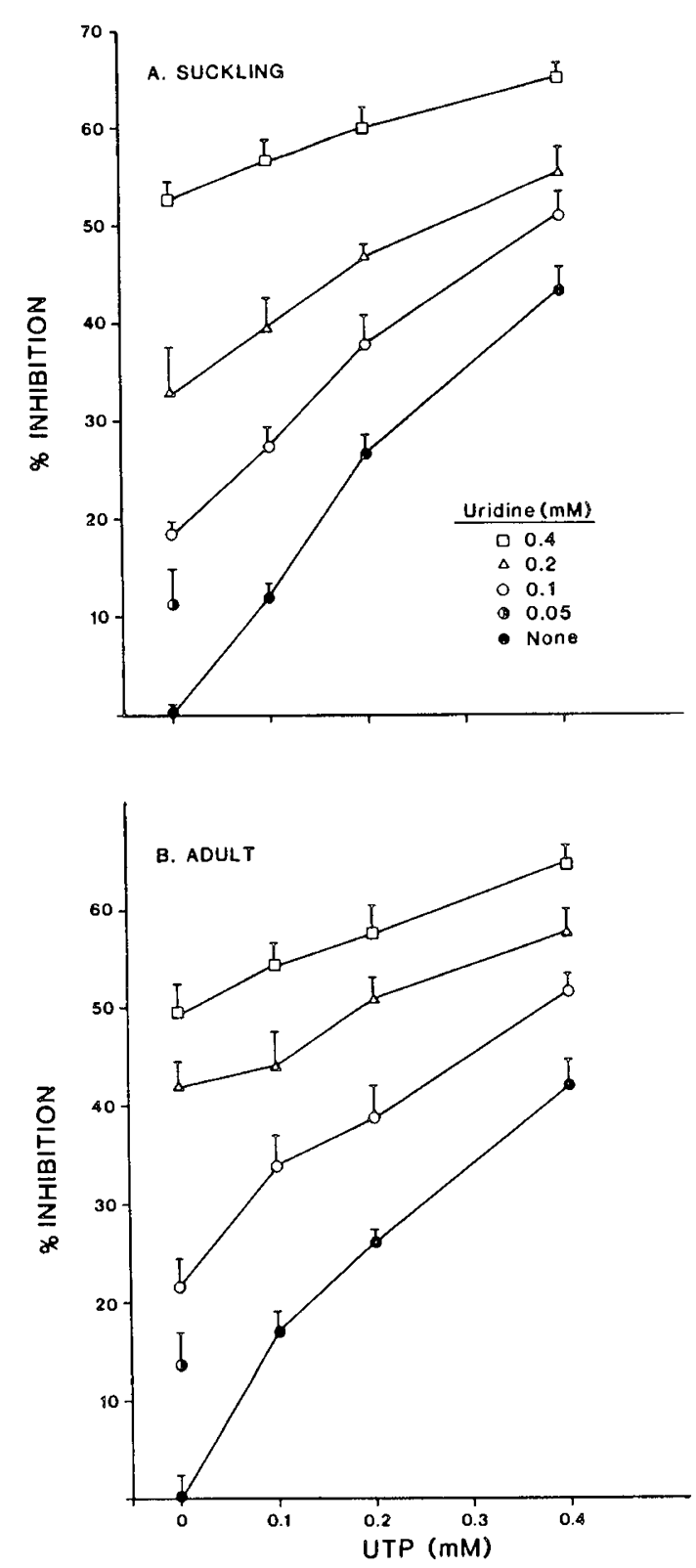

Fig. 3. Combined effect of uridine and UTP on transferase in suckling (upper panel) and adult (lower panel) rat liver. Data shown are averages \pm SEM for three to four animals.

inhibition by uridine and UTP is similar in both liver and ovary where the basal activities are normally high. The data suggest that the brain enzyme with a low sp act may be more responsive to uridine inhibition. For both uridine and UTP, the reactivity of the enzyme of adult and newborn brain is the same, which parallels the finding in liver.

The kinetic data indicate that both pyrimidine compounds are competitive inhibitors of brain transferase with a $k_{i}$ of $0.15-0.20$ $\mathrm{mM}$, very much like that observed for hepatic enzyme $(9,10)$. Only uridine and nucleotides with a pyrimidine base and a carbonyl function at positions 2 and 4 are competitive inhibitors of UDPglucose. Indeed, UDPglucose itself produces substrate inhibition (13). Our observations stress the importance of the uridine moiety of UDPglucose for binding to the enzyme as part of the proposed "ping-pong" mechanism involved (21). The fact that uridine, however, is a nonlinear competitive inhibitor of the hepatic enzyme whereas UTP is a linear competitive inhibitor suggests that achievement of complete inhibition as seen with UTP (9) requires both the uridine and the phosphate compo- nents. Apparently, both are involved in blocking the catalytic activity of the enzyme. The data in Figure 3 in which uridine at higher concentrations blunts the UTP inhibition are consistent with the nucleoside preventing UTP from exercising its effect at the phosphate binding site.

The concentration of UTP in rat (22) and mouse liver (20) has been reported to be as high as $0.3 \mathrm{mM}$. Its concentration in

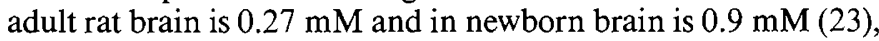
levels at which we report $50 \%$ or more inhibition of transferase sp act in vitro. An extrapolation of this degree of inhibition to the intact cell suggests that the enzyme functions under "braking" conditions for its activity in both liver and brain.

Tissue levels of uridine in the rat have not been reported when uridine nucleotides have been analyzed (23). Plasma levels in humans however, are known to be in the 4-6 $\mu \mathrm{M}$ range (24). The administration of oral uridine to patients with galactosemia has raised the plasma level to as high as $70-80 \mu \mathrm{M}(7,8)$ which is in the range where hepatic transferase is inhibited (Fig. 3). Tissue levels of uridine after chronic administration of the compound to humans are not known. An efficient transport system for uridine has been reported in the blood brain barrier (25), and a transport system for uridine is active in mouse brain slices (26). Because rat brain transferase is sensitive to inhibition by uridine, it is possible that an increase in circulating uridine might have a significant effect on its content in brain and the ability to metabolize galactose-1-phosphate. This could be especially significant when combined with the effect of high intracellular UTP normally present (23).

As shown in the rat, the administration of uridine contributes to an increase in hepatic cellular UTP (12). In addition, we have reported that perfusion of suckling rat liver with $1 \mathrm{mM}$ uridine raises the cellular level of UTP threefold from 0.06 to $0.19 \mu \mathrm{mol}$ per gram wet wt (10). Concomitant perfusion of galactose resulted in a significant increase in galactose-1-phosphate. The data suggested that uridine directly and indirectly by elevating UTP acted to impair hepatic galactose metabolism. The only report of a uridine effect on galactose metabolism in human tissue is that of Segal et al. (11) who found that uridine markedly inhibited the oxidation of $1-\left[{ }^{14} \mathrm{C}\right]$ galactose by normal red cells to ${ }^{14} \mathrm{CO}_{2}$. Both uridine and UTP are known to be inhibitors of UDPglucose binding to human liver UDPglucose:dolichylphosphate glucosyltransferase (27) with a $\mathrm{k}_{\mathrm{i}}$ of $0.17 \mathrm{mM}$, which is like that observed for rat galactose-1-phosphate uridyltransferase.

The totality of our findings that uridine and its related nucleotides inhibit transferase indicates that a cautious approach to uridine administration to galactosemic patients should be pursued. If the theory of Gitzelmann et al. (5) is correct that continued galactose toxicity is due to endogenous production of galactose-1-phosphate from UDPgalactose formed from UDPglucose, any inhibition of residual transferase activity in the cells of galactosemic patients by uridine or resulting uridine nucleotides would impair disposition of the sugar phosphate and increase the risk of toxic manifestations. Despite the absence of transferase in red blood cells, galactosemic patients when given $\left[{ }^{14} \mathrm{C}\right]$ galactose are capable of oxidizing it to ${ }^{14} \mathrm{CO}_{2}(28,29)$, thereby attesting to their having residual galactose-metabolizing ability in some tissues. Moreover, if uridine administration raises tissue levels of UDPgalactose, the possibility of increased toxicity may be compounded by UDPgalactose pyrophosphorylase activity, generating greater amounts of galactose-1-phosphate. The fact that $\mathrm{Ng}$ and colleagues report no increase in red cell galactose-1-phosphate levels in uridine-treated patients (30) does not rule out this possibility in brain or other tissues. The red cell in most patients contains no enzyme activity for uridine to inhibit (11) and, indeed, the factors regulating the steady-state level of the sugar phosphate in affected red cells are not well understood. We believe that long-term uridine therapy in galactosemia should be conducted with judicious reservation and in a manner such that resulting tissue uridine and uridine nucleotides do not inhibit transferase activity. 
Acknowledgments. The authors thank Paul Gallagher for the statistical analysis and Isabella A. Fisher for typing the manuscript.

\section{REFERENCES}

1. Waggoner DD, Buist NRM, Donnell GN 1990 Long-term prognosis in galactosaemia: results of a survey of 350 cases. J Inherited Metab Dis 13:802-818

2. Friedman JH, Levy HL, Boustany RM 1989 Late onset of distinct neurologic syndromes in galactosemic siblings. Neurology 39:741-742.

3. Kinoshita JH, Merola LO 1964 Hydration of the lens during the development of galactose cataract. Invest Ophthalmol 3:577-584

4. Segal S 1989 Disorders of galactose metabolism. In: Scriver $\mathrm{CH}$, Beaudet AL, Sly WS, Valle D (eds) The Metabolic Basis of Inherited Diseases, Vol II, 6th Ed. McGraw-Hill, New York, pp 453-480

5. Gitzelmann R, Hansen RG, Steinmann B 1975 Biogenesis of galactose, a possible mechanism of self-intoxication in galactosemia. In: Hommes FA, Van den Berg CJ (eds) Normal and Pathological Development of Energy Metabolism. Academic Press, London, pp 25-37

6. Ng WG, Xu YK, Kaufman FR, Donnell GN 1989 Deficit of uridine diphosphate galactose in galactosaemia. J Inherited Metab Dis 12:257-266

7. Kaufman FR, Ng WN, Xu YK, Guidici T, Kaleita TA, Donnell GN 1989 Normalization of uridine diphosphate galactose (UDPGal) levels with oral uridine in patients(PTS) with classical galactosemia. Clin Res 37:184A(abstr)

8. Kaufman FR, Ng WN, Xu YK, Guidici T, Kaleita TA, Donnell GN 1989 Treatment of patients (PTS) with classical galactosemia $(\mathrm{G})$ with oral uridine. Pediatr Res 25:834(abstr)

9. Segal S, Rogers S 1971 Nucleotide inhibition of mammalian liver galactose-1phosphate uridyltransferase. Biochim Biophys Acta 250:351-360

10. Rogers SR, Bovee BW, Segal S 1989 Effect of uridine on hepatic galactose-1phosphate uridyltransferase. Enzyme 42:53-60

11. Segal S, Roth H, Blair A 1966 Observations on the influence of orotic acid on galactose metabolism in congenital galactosemia. $J$ Pediatr 68:135-138

12. Keppler DOR, Pausch J, Decker K 1974 Selective uridine triphosphate deficiency induced by D-galactosamine in liver and reversed by pyrimidine nucleotide precursors: effect on ribonucleic acid synthesis. J Biol Chem 249:211-216

13. Bertoli D, Segal S 1966 Developmental aspects and some characteristics of mammalian galactose-1-phosphate uridyltransferase. J Biol Chem 241:40234029
14. Rogers S, Segal S 1981 Changing activities of galactose-metabolizing enzymes during perfusion of suckling rat liver. Am J Physiol 240:E333-E339

15. Rogers S, Bovee BW, Saunders S, Segal S 1989 Activity of hepatic galactosemetabolizing enzymes in the pregnant rat and fetus. Pediatr Res 25:161-166

16. Rogers SR, Bovee BW, Saunders SL, Segal S 1989 Galactose as a regulatory factor of its own metabolism by rat liver. Metabolism 38:810-815

17. Lineweaver H, Burk DJ 1934 The determination of enzyme dissociation constants. J Am Chem Soc 56:658-666

18. Dixon M 1953 The determination enzyme inhibitor constants. Biochem J 55:170-177

19. Webb JL 1963 Enzymes and Metabolic Inhibitors, Vol I. Academic Press, New York

20. Keppler D, Rudigier J, Decker K 1970 Enzymatic determination of uracil nucleotides in tissues. Anal Biochem 38:105-114

21. Hester LS, Raushel FM 1987 Analysis of ping-pong reaction mechanisms by positional isotope exchange: application to galactose-1-phosphate uridyltransferase. J Biol Chem 262:12092-12095

22. Keppler DO, Schulz-Holstege C, Fauler J 1982 Uridylate trapping, induction of UTP deficiency, and stimulation of pyrimidine synthesis de novo by Dgalactosone. Biochem J 206:139-146

23. Hisanaga $\mathrm{K}$, Onodera $\mathrm{H}$, Kogure $\mathrm{K} 1986$ Changes in levels of purine and pyrimidine nucleotides during acute hypoxia and recovery in neonatal rat brain. J Neurochem 47:1344-1350

24. Webster DR, Simmonds HA 1981 Pyrimidine and purine metabolites in ornithine carbamyl transferase deficiency. J Inherited Metab Dis 4:27-3

25. Cornford EM, Oldendorf WH 1975 Independent blood-brain barrier transport systems for nucleic acid precursor. Biochim Biophys Acta 394:211-219

26. Banay-Schwartz M, de Gugman T, Lajtha A 1980 Nucleoside uptake by slices of mouse brain. J Neurochem 35:544-551

27. Matern H, Matern S 1989 Control of dolichylphosphoglucose formation in human liver microsomes. Kinetic and inhibition studies of nucleoside, nucleotide and analogues of UDPglucose. Biochim Biophys Acta 1004:6772

28. Segal S, Blair A, Roth H 1965 The metabolism of galactose by patients with congenital galactosemia. Am J Med 38:62-70

29. Segal S, Cuatrecasas P 1968 The oxidation of $\mathrm{C} 14$ galactose by patients with congenital galactosemia: evidence for a direct oxidative pathway. Am J Med 44: 340-347

30. Ng WG, Xu YK, Kaufman FR, Donnell GN 1990 Uridine diphosphate glucose and uridine diphosphate galactose in galactosemia. [letter] J Pediatr 117:840842 